\title{
Preventing Human Immunodeficiency Virus Infection Among Sexual Assault Survivors in Cape Town, South Africa: An Observational Study
}

\author{
Michelle E. Roland • Landon Myer • Lorna J. Martin • \\ Anastasia Maw • Priya Batra • Elizabeth Arend • \\ Thomas J. Coates $\cdot$ Lynette A. Denny
}

Published online: 8 February 2011

(c) The Author(s) 2011. This article is published with open access at Springerlink.com

\begin{abstract}
We describe 131 South African sexual assault survivors offered HIV post-exposure prophylaxis (PEP). While the median days completed was 27 (IQR 27, 28), $34 \%$ stopped PEP or missed doses. Controlling for baseline symptoms, PEP was not associated with symptoms $(\mathrm{OR}=1.30,95 \% \mathrm{CI}=0.66,2.64)$. Factors associated with unprotected sex included prior unprotected sex $(\mathrm{OR}=6.46,95 \% \mathrm{CI}=3.04,13.74)$, time since the assault $(\mathrm{OR}=1.33,95 \% \mathrm{CI}=1.12,1.57)$ and age $(\mathrm{OR}=1.30$, $95 \% \mathrm{CI}=1.08,1.57)$. Trauma counseling was protective $(\mathrm{OR}=0.18,95 \% \mathrm{CI}=0.05,0.58)$. Four instances of seroconversion were observed by 6 months (risk $=3.7 \%$, $95 \% \mathrm{CI}=1.0,9.1$ ). Proactive follow-up is necessary to increase the likelihood of PEP completion and address the mental health and HIV risk needs of survivors. Adherence
\end{abstract}

M. E. Roland ( $\square)$

Positive Health Program at San Francisco General Hospital, University of California San Francisco, Ward 84,

995 Potrero Avenue, San Francisco, CA 94110, USA

e-mail: Michelle.Roland@cdph.ca.gov

L. Myer

School of Public Health \& Family Medicine,

University of Cape Town, Cape Town, South Africa

L. J. Martin

Department of Forensic Medicine, University of Cape Town,

Cape Town, South Africa

\section{A. Maw}

Department of Psychology, University of Cape Town,

Cape Town, South Africa

\section{Myer}

International Center for AIDS Care and Treatment Programs and Department of Epidemiology, Mailman School of Public Health, Columbia University, New York, NY, USA interventions and targeted risk reduction counseling should be provided to minimize HIV acquisition.

Keywords Human immunodeficiency virus . Post-exposure prophylaxis - Sexual assault . Adherence $\cdot$ Risk behavior

\section{Introduction}

Antiretroviral therapy reduces HIV transmission risk following needle-stick exposures [1]. Guidelines in many countries, including South Africa, also recommend postexposure prophylaxis (PEP) following potential sexual exposure to HIV [2-14]. In reports from North America,

\author{
P. Batra \\ Columbia University College of Physicians and Surgeons, \\ New York, NY, USA \\ E. Arend \\ Gender Action, Washington, DC, USA \\ T. J. Coates \\ Division of Infectious Diseases, UCLA Program \\ in Global Health, University of California Los Angeles, \\ Los Angeles, CA, USA \\ L. A. Denny \\ Department of Obstetrics \& Gynaecology, \\ University of Cape Town, Cape Town, South Africa
}


Europe and Australia, PEP acceptance, completion and HIV testing rates are generally lower following sexual assault than following consensual sexual exposures [1523]. These studies describe Western settings where HIV prevalence is relatively low in the general public but substantially higher among the men-who-have-sex-with-men who have been studied following consensual sexual exposures. Sexual assault survivors may be more motivated to accept and adhere to PEP in higher HIV prevalence areas.

However, rape survivors may be too traumatized when they seek immediate post-rape care to be able to fully understand the risks and benefits of PEP [16]. Even in higher HIV prevalence settings like Kenya and South Africa, PEP adherence is often poor [24, 25]. In Kenya, survivors' willingness to accept and adhere to PEP was affected by the difficulty clinicians have discussing rape and encouraging communication with survivors [26]. South African survivors report that counseling and other forms of emotional and psychological support are important components of PEP provision [27].

As in many countries, South African health care providers often lack the training to provide quality care for rape survivors, provider attitudes may be negative, there are often no post-rape care protocols, service delivery may be uncoordinated, and there is little trauma counseling and psychosocial referral [28]. A cross-sectional study of 124 doctors and nurses in all nine South African provinces found that one-third did not view rape as a serious medical condition, and less than one-third had ever been trained on caring for rape survivors [29]. Almost $60 \%$ reported that their hospital did not have a protocol for post-rape care, and less than half reported that they referred rape survivors for counseling.

In many countries and localities, facilities that initiate PEP after sexual assault may refer clients to specialized local clinics for the remainder of their PEP course and follow-up. There is usually no formal tracking system between or within these clinics and there is no active retention approach. In contrast, when Brazilian sexual assault survivors were followed in a more structured system, PEP completion and follow-up HIV testing rates were marginally higher than generally reported in the literature [30]. And in a more recent study at a rural South African hospital, survivors were three times more likely to complete the entire 28 day course when they received comprehensive care from specially trained nurses than in the pre-intervention period [28].

Maximizing PEP completion and adherence following sexual assault in South Africa and elsewhere may warrant the development of proactive follow-up systems. Additionally, if some assault survivors are also exposed to HIV through consensual sexual relationships, they may benefit from risk reduction counseling modeled after that provided following consensual exposures [22, 23, 31]. Thus, we designed a proactive, flexible, nurse-driven follow-up system for sexual assault survivors in Cape Town, South Africa. Within the context of such proactive follow-up, we describe PEP adherence and predictors of non-adherence, symptoms associated with PEP use, predictors of HIV risk prior to and following the assault, follow-up HIV testing rates and instances of seroconversion. This information can be used to continue to improve upon PEP service delivery systems for sexual assault survivors in South Africa and elsewhere by identifying survivor characteristics associated with poorer outcomes and developing and testing new strategies to improve follow-up and adherence and reduce subsequent HIV exposures and seroconversion. It also provides critical information about the level of support needed to retain sexual assault survivors for ongoing HIV prevention and testing that can inform public health policymakers.

\section{Methods}

\section{Study Design}

This was an observational study of sexual assault survivors who were offered 28 days of zidovudine and lamivudine within $72 \mathrm{~h}$ of an assault associated with potential HIV transmission. PEP, sexually transmitted infection prophylaxis and emergency contraception were all provided free of charge. PEP medications were dispensed as follows: at the initial clinic visit, a 3 or 4 day supply was provided by a non-research clinician or a 7 day supply was provided by a research clinician. At the first clinical follow-up visit for those seen initially by non-study staff, the remainder of the first week's supply was dispensed. At the week one study visit, the remainder of the full 28-day course was dispensed. Though nurses did not provide formal adherence counseling, they were encouraged to discuss specific adherence strategies with participants. Study nurses also referred participants for rape counseling.

\section{Setting}

Initial care was provided in a hospital-based rape treatment center outside of Cape Town, South Africa by research or non-research clinicians (depending upon research staff availability). Follow-up visits with research nurses over the course of 6 months were offered at the rape treatment center, a research office in Cape Town, a primary care health centre in a neighboring township, or at home. Both the longer duration of follow-up and the choice of multiple follow-up sites differ from routine practice. 
Participants

We maintained an anonymous record of all sexual assault survivors presenting for care who were 14 years of age or older. We enrolled participants for up to 5 days after rape examination. Sexual assault survivors who had experienced receptive vaginal or anal intercourse without a condom or with a condom that broke or came off, receptive oral sex with ejaculation, or perpetrator blood or ejaculate on a mucous membrane or non-intact skin were eligible. Patients found to be infected with HIV by self-report or an appropriate testing algorithm were excluded. Baseline and follow-up HIV testing were not required.

Rape center staff recruited participants after clinical and forensic examinations and provision of the initial PEP dose. If the initial visit was outside of research hours, patients were asked to provide written consent to be contacted by telephone and/or home visit for recruitment. Patients were also recruited at their first routine clinical follow-up visit. Participation of patients who were between 14 and 18 years of age required guardian consent.

The Committee on Human Research at the University of California, San Francisco and the Research Ethics Committee at University of Cape Town approved the study protocols. Each participant provided written informed consent.

\section{Demographic Data and Sexual Assault Characteristics}

To minimize intrusiveness and interview time, study nurses obtained demographic data and assault details from standard medico-legal forms. Additional data were obtained by interviewer-administered questionnaire.

\section{Measuring Adherence, Symptoms and Risk Behaviors}

We calculated the total number of days of PEP completed at each visit using self-report of the last day that PEP was taken, and the study record of PEP initiation. Comprehension of dosing instructions and reasons for missed doses were queried. Symptoms and sexual behaviors were elicited with a structured interviewer-administered questionnaire at study enrollment (baseline) and at weeks one and four and months three and six. Symptoms were graded using modified World Health Organization criteria. At week one, study nurses asked about the total number of partners with whom the participant had protected or unprotected intercourse (vaginal, oral and anal) in the 6 months prior to the assault. For each unprotected sex partner, we also asked about the partner's HIV status. Interval sexual histories were obtained at subsequent visits.
Laboratory Evaluations

HIV antibody testing, with pre- and post-test counseling, was offered at baseline and months three and six. Those who declined HIV testing were encouraged to be tested at subsequent visits. White blood cell count, hemoglobin and the liver enzyme aspartate alanine aminotrasferase (ALT) were measured at baseline, week four, and months three and six. Female participants were offered pregnancy tests at enrollment and week four.

Incentives and Follow-up

We provided a 50 Rand (approximately US \$8.50) food voucher at week four and months three and six. For participants who did not choose home visits, transportation costs were reimbursed. With participant consent, appointment reminders were provided by telephone at 1 week and 1 day prior to visits. For missed visits, followup contact was attempted for up to 5 days, at different times of day. None of these are the standard, non-research practice.

\section{Statistical Methods}

We used Fisher's exact test or the $t$-test in univariate analyses and multivariable logistic regression models to examine predictors of PEP non-adherence and post-assault HIV risk behavior. Non-adherence was defined as either PEP discontinuation prior to 28 days, self-report of any missed dose between days 3 and 7, and/or loss to follow-up prior to the week one study visit. HIV risk behavior was defined as unprotected vaginal intercourse reported at the three or 6 month visit.

We included the following variables in all univariate analyses: age, ethnicity, education, employment, household income, living/not living with sexual partner, children at home, pregnancy, perpetrator known, perpetrator was a husband or boyfriend, prior unprotected intercourse, prior HIV testing and rape counseling received within one week. In the adherence model, we also included time to PEP initiation and symptoms at baseline. In the ongoing HIV risk behavior models we also included symptoms and whether rape counseling was received by 4 weeks. Multivariable models were constructed using backward selection of variables associated with a $P$-value of 0.20 or less in univariate models. The association of PEP use with symptoms was assessed in a repeated measures model using generalized estimated equations. 
Table 1 Participant characteristics

\begin{tabular}{|c|c|}
\hline Characteristics & Participants \\
\hline Age, years (median; IQR) & $21 ;[17-24]$ \\
\hline Female sex, $n(\%)$ & $132(98)$ \\
\hline \multicolumn{2}{|l|}{ Race/ethnicity, $n(\%)$} \\
\hline African & $103(76)$ \\
\hline "Colored" & $32(24)$ \\
\hline \multicolumn{2}{|l|}{ Primary language, $n(\%)$} \\
\hline Xhosa & $101(75)$ \\
\hline Afrikaans & $26(19)$ \\
\hline English & $6(5)$ \\
\hline Zulu & $2(1)$ \\
\hline \multicolumn{2}{|l|}{ Marital status, $n(\%)$} \\
\hline Single/never married & $116(86)$ \\
\hline Married & $5(4)$ \\
\hline Separated & $6(4)$ \\
\hline Divorced & $6(4)$ \\
\hline Live-in partner & $2(1)$ \\
\hline \multicolumn{2}{|l|}{ Children, $n(\%)$} \\
\hline None & $87(64)$ \\
\hline $1-2$ & $41(30)$ \\
\hline$\geq 3$ & $7(6)$ \\
\hline Participant's children living in home, $n(\%)$ & $33(24)$ \\
\hline Any others living in home (median; IQR) & $5 ;[3,6]$ \\
\hline Pregnant at enrollment, $n(\%)$ & $4(3)$ \\
\hline \multicolumn{2}{|l|}{ Education, $n(\%)$} \\
\hline None through grade 6 & $10(7)$ \\
\hline Grade $7-11$ & $104(77)$ \\
\hline High school graduate & $11(8)$ \\
\hline College/university/graduate school & $10(9)$ \\
\hline Employed, $n(\%)$ & $29(21)$ \\
\hline \multicolumn{2}{|l|}{ Household income (Rand), $n(\%)(\mathrm{R} 1=\mathrm{US} \$ 6)$} \\
\hline$\leq \mathrm{R} 5,000$ & $19(14)$ \\
\hline $\mathrm{R} 5,001-10,000$ & $30(22)$ \\
\hline R10,001-20,000 & $36(27)$ \\
\hline $\mathrm{R} 10,001-30,000$ & $22(16)$ \\
\hline R30,001-40,000 & $14(10)$ \\
\hline$>\mathrm{R} 40,000$ & $14(10)$ \\
\hline
\end{tabular}

\section{Results}

Participants, Study Size and Descriptive Data

During the study period of March to September 2004, 514 patients were seen at the rape center. Of these patients, 135 (26\%) eligible participants were enrolled; 131 of those (97\%) initiated PEP. Of the 514, 103 (20\%) were seen after hours and did not provide consent to be contacted and 59 (14\%) declined study participation. Eight (2\%) did not
Table 2 Characteristics of the assault and potential HIV exposure

\begin{tabular}{|c|c|}
\hline Characteristic & $N(\%)$ \\
\hline Any perpetrator known to participant & $84(46)$ \\
\hline Neighbor & $20(15)$ \\
\hline Friend & $17(13)$ \\
\hline Previous boyfriend & $8(6)$ \\
\hline Lives with perpetrator & $5(4)$ \\
\hline Abducted & $77(57)$ \\
\hline \multicolumn{2}{|l|}{ Location of assault } \\
\hline Perpetrator's home & $55(41)$ \\
\hline Open space & $45(33)$ \\
\hline Participant's home & $17(13)$ \\
\hline Other & $18(13)$ \\
\hline Any weapon used & $68(50)$ \\
\hline Gun & $29(21)$ \\
\hline Knife & $30(39)$ \\
\hline Bottle/screwdriver/other & $16(12)$ \\
\hline Alcohol use in $3 \mathrm{~h}$ prior to assault & $34(25)$ \\
\hline Alcohol use between 3 and $24 \mathrm{~h}$ of assault & $3(2)$ \\
\hline Drug use within $24 \mathrm{~h}$ of assault & $3(2)$ \\
\hline \multicolumn{2}{|l|}{ Potential HIV exposure route ${ }^{\mathrm{a}}$} \\
\hline Vaginal receptive intercourse & $128(97)$ \\
\hline Anal receptive intercourse & $20(15)$ \\
\hline Oral receptive intercourse with ejaculation & $5(4)$ \\
\hline Unconscious at time of assault & $4(3)$ \\
\hline Total perpetrators & 193 \\
\hline \multicolumn{2}{|l|}{ Number of perpetrators } \\
\hline 1 & $102(76)$ \\
\hline 2 & $21(16)$ \\
\hline$>2$ & $12(9)$ \\
\hline HIV status of perpetrator unknown & $187(97)$ \\
\hline Prior intercourse with any perpetrator & $13(10)$ \\
\hline
\end{tabular}

${ }^{\text {a }}$ No condom used or condom broke or came off

have an eligible exposure, $60(17 \%)$ were not contacted within 5 days of the initial exam, $28(8 \%)$ were less than 14 years old, 15 (4\%) between 14 and 18 years old did not obtain guardian consent, 13 (4\%) were unable to follow up and $14(4 \%)$ were unable to consent. Data were unavailable for the remaining 79 non-study patients. Characteristics of the 135 study participants are shown in Table 1.

Assaults often involved abduction and violence (Table 2). Forty-six percent of perpetrators were known, commonly being neighbors, friends or ex-boyfriends. The perpetrator's HIV status was usually unknown (97\%). Anal or oral penetration was reported infrequently.

PEP Initiation and Adherence

The median time to PEP initiation was $13 \mathrm{~h}$ [IQR 8, 22]. PEP was initiated within less than $24 \mathrm{~h}$ in 103 (79\%) 
Table 3 PEP adherence

\begin{tabular}{|c|c|}
\hline Adherence characteristic & $N(\%)$ \\
\hline $\begin{array}{l}\text { Lost to follow-up at week } 1 \text {, discontinued, } \\
\text { or missed any dose }\end{array}$ & $45(34)$ \\
\hline Lost to follow-up at week $1^{\mathrm{a}}$ & $9(7)$ \\
\hline Discontinued PEP before 28 days $^{\mathrm{b}}$ & $7(5)$ \\
\hline Missed any dose in 4 days prior to week 1 visit & $29(25)$ \\
\hline 1 dose & $10(8)$ \\
\hline 2 doses & $12(9)$ \\
\hline$\geq 3$ doses & $7(5)$ \\
\hline $\begin{array}{l}\text { PEP dosing beyond } 28 \text { days and no missed doses } \\
\text { at week } 1\end{array}$ & $4(3)$ \\
\hline $\begin{array}{l}\text { Lost to follow-up between weeks } 1 \text { and } 4 \text { with all } \\
\text { PEP dispensed }\end{array}$ & $18(14)$ \\
\hline \multicolumn{2}{|c|}{ Reasons for any missed dose in prior 4 days at week 1 visit } \\
\hline Forgot & $18(62)$ \\
\hline Away from home & $14(54)$ \\
\hline Didn't want people to notice & $5(17)$ \\
\hline Felt sick & $5(17)$ \\
\hline Busy & $4(14)$ \\
\hline Change in routine & $3(10)$ \\
\hline Side effects & $2(7)$ \\
\hline Slept through dose & $2(7)$ \\
\hline Felt depressed & $2(7)$ \\
\hline $\begin{array}{l}\text { Thought pills would work even if a few were } \\
\text { missed }\end{array}$ & $1(3)$ \\
\hline Feeling overwhelmed & 0 \\
\hline Pill burden & 0 \\
\hline
\end{tabular}

a $10-12$ days of medications had been dispensed to the nine participants who were lost to follow-up prior to the week 1 visit

b 1 additional participant discontinued PEP after 2 days at the direction of the study physician and is not considered non-adherent

participants. The median days of PEP completed was 27 [IQR 27, 28]. However, 34\% of participants had either stopped taking PEP, missed one or more doses on days 3-7, or were lost to follow-up prior to the week one study visit (Table 3). Nineteen (15\%) participants reported missing two or more doses in the prior week. Reasons commonly cited for missed doses included forgetting and being away from home. All participants reported good understanding of dosing instructions. In univariate analyses, there was a non-significant trend towards better adherence among those with more education and those who reported attending rape counseling ( $P=0.090$ and 0.129 , respectively). These trends were stronger in the multivariate model $(P=0.057$ and 0.069). No other variables were associated with adherence.

\section{Symptoms and Laboratory Abnormalities}

Symptoms were reported by $70 \%$ of participants, most commonly fatigue, nausea and headaches. The median time to study enrollment and initial symptom data collection was 3 days [IQR 2,3] following PEP initiation. At the baseline study visit, significantly more participants who had not yet initiated PEP, or had initiated PEP within the previous $24 \mathrm{~h}$, reported symptoms compared to participants who had initiated PEP more than $24 \mathrm{~h}$ prior $(52 \%$ versus $17 \% ; P=0.003$, Table 4). In multivariate logistic regression models controlling for baseline symptoms, PEP was not associated with on-treatment symptoms $(\mathrm{OR}=1.30$, $95 \% \mathrm{CI}=0.66,2.64)$. Symptoms at baseline were associated with subsequent symptoms in models including all participants who took PEP $(\mathrm{OR}=2.68,95 \% \mathrm{CI}=1.25$, 5.74) and when restricting the analysis to just those 23 participants who had not yet initiated PEP or had initiated PEP within $24 \mathrm{~h}$ of the baseline visit $(\mathrm{OR}=8.03,95 \%$ $\mathrm{CI}=1.8,35.5$ ). There were no laboratory abnormalities more severe than Grade 2 in any participants taking PEP. Four participants were pregnant at enrollment. A total of six incident pregnancies were detected by the 6 month visit.

\section{HIV Risk Behaviors}

In the 6 months prior to the assault, 71 (58\%) participants reported vaginal intercourse, which was unprotected in fifty participants. Among these, 32 (64\%) did not know the HIV status of their partners. At week four, 44 participants (38\%) reported having any intercourse since the prior visit, $61 \%$ of whom reported unprotected vaginal intercourse. Half of these cases did not know the HIV status of their partners.

Table 4 Proportion of participants reporting $\geq$ grade 2 symptoms stratified by PEP initiation within $24 \mathrm{~h}$ of interview

\begin{tabular}{|c|c|c|c|c|c|}
\hline Characteristic & $\begin{array}{l}\text { Baseline } \\
(n=135) \%\end{array}$ & $\begin{array}{l}\text { Week } 1 \\
(n=123) \%\end{array}$ & $\begin{array}{l}\text { Week } 4 \\
(n=117) \%\end{array}$ & $\begin{array}{l}\text { Month } 3 \\
(n=116) \%\end{array}$ & $\begin{array}{l}\text { Month 6 } \\
(n=104) \%\end{array}$ \\
\hline Any symptom & 46 & 34 & 27 & 24 & 32 \\
\hline $\begin{array}{l}\text { PEP not yet initiated/initiated } \\
\text { within } 24 \mathrm{~h}(n=23)\end{array}$ & 52 & 48 & 23 & 30 & 25 \\
\hline PEP initiated $>24$ h prior $(n=112)$ & 17 & 31 & 28 & 23 & 31 \\
\hline$P$-value & 0.003 & 0.147 & 0.791 & 0.426 & 0.787 \\
\hline
\end{tabular}


Table 5 Sexual behavior

\begin{tabular}{lllll}
\hline & $\begin{array}{l}\text { Baseline } \\
(n=123) \%\end{array}$ & $\begin{array}{l}\text { Week 4 } \\
(n=117)\end{array}$ & $\begin{array}{l}\text { Month 3 } \\
(n=116) \%\end{array}$ & $\begin{array}{l}\text { Month 6 } \\
(n=104) \%\end{array}$ \\
\hline Any sexual intercourse, \% all & 58 & 38 & 53 & 64 \\
$\begin{array}{l}\text { 1 partner, \% sexually active } \\
\begin{array}{l}\text { Unprotected intercourse, } \\
\text { \% sexually active }\end{array}\end{array}$ & 93 & 100 & 98 & 97 \\
$\begin{array}{l}\text { Partner HIV status unknown, } \\
\% \text { unprotected intercourse }\end{array}$ & 64 & 61 & 62 & 60 \\
\hline
\end{tabular}

Table 6 Predictors of unprotected sexual intercourse in the 6 months following the assault

\begin{tabular}{lcc}
\hline Characteristic & Unadjusted odds ratio $(95 \% \mathrm{CI})$ & $P$-value \\
\hline Age & $1.04(1.02,1.07)$ & 0.000 \\
Primary language & $1.00(0.65,1.57)$ & 0.969 \\
Education & $1.084(0.639,1.841)$ & 0.764 \\
Employed & $0.381(0.244,0.594)$ & 0.000 \\
Income & $0.697(0.462,1.051)$ & 0.085 \\
Living with primary sexual partner & $4.33(1.71,11.0)$ & 0.002 \\
Pregnant at enrollment & $0.093(0.020,0.432)$ & 0.002 \\
Any perpetrator known to participant & $0.82(0.56,1.21)$ & 0.323 \\
Perpetrator was husband or boyfriend & $0.79(0.39,1.59)$ & 0.506 \\
Unprotected intercourse prior to assault & $15.5(9.48,25.34)$ & 0.000 \\
Symptoms ( $\geq$ grade 2$)$ & $1.23(0.811,1.85)$ & 0.334 \\
Attended trauma counseling & $0.64(0.43,0.94)$ & 0.024 \\
Time since assault & $1.00(0.998,1.004)$ & 0.476 \\
\hline Characteristic & Adjusted odds ratio $(95 \% \mathrm{CI})$ & $P$-value \\
\hline Age (per 5 year increments) & $1.30(1.08,1.57)$ & 0.006 \\
Unprotected intercourse prior to assault & $6.46(3.04,13.74)$ & 0.000 \\
Attended trauma counseling & $0.18(0.05,0.58)$ & 0.004 \\
Time since assault (in 30 day increments) & $1.33(1.12,1.57)$ & 0.001 \\
\hline
\end{tabular}

At months three and six, increasing proportions of participants reported intercourse. This was mostly unprotected and with partners of unknown HIV status (Table 5). In the multivariate model, factors associated with unprotected sex in the 6 months following the assault included unprotected sex in the 6 months prior to the assault (OR $=6.46,95 \%$ $\mathrm{CI}=3.04,13.74$ ), time since the assault (per 30-day increments, $\mathrm{OR}=1.33,95 \% \mathrm{CI}=1.12,1.57$ ) and age (per 5-year increments $\mathrm{OR}=1.30,95 \% \mathrm{CI}=1.08,1.57$, Table 6). Attending trauma counseling was protective $(\mathrm{OR}=0.18,95 \% \mathrm{CI}=0.05,0.58)$.

\section{Baseline and Follow-up HIV Testing} and Seroconversion

Two participants declined HIV testing at baseline but accepted it at their next visits. Testing was declined by three and 16 participants at months three and six, respectively. Those who declined cited not wanting to know their HIV status, an inability to cope with a positive result, or too short a time since the last test. In total, $81 \%$ of participants had an HIV test at months three or six. Four seroconversions were observed by 6 months (risk $=3.7 \%$; $95 \%$ $\mathrm{CI}=1.0,9.1)$. Two occurred in participants who did not report other unprotected sex and thus were likely PEP failures. One of these occurred in the context of excellent reported adherence and the other with incomplete adherence to PEP. The other instances were likely to have resulted from ongoing exposures.

\section{Service Delivery Issues}

Sixty-one percent of follow-up visits occurred at the rape treatment center, twenty percent at home, and $19 \%$ at the research office in town. Missed visit tracing was required for 52 participants; 161 tracing attempts resulted in 45 participants returning for follow-up. Those participants missing visits cited being too busy, work-related issues, forgetting, family problems, having moved, transportation/ money problems and school-related issues. 
At least one rape counseling session was attended by 75 (56\%) participants. At the baseline visit, staff referred 128 (95\%) individuals for rape counseling; 61 (50\%) of those who completed the week one visit attended counseling. At week one, week four and month three, 104 (90\%), 79 $(81 \%), 46(98 \%)$ participants attending each visit had been referred, respectively; 67 (64\%), 52 (64\%), and 28 (61\%) subsequently attended rape counseling.

\section{Discussion}

When PEP and rape counseling referrals were provided by nurses trained in intensive follow-up, PEP completion and follow-up HIV testing rates were very high; 74\% were known to have completed the full PEP course and an additional $14 \%$ received the entire 28 day course and may have completed it even though they were lost to follow-up. Still, $25 \%$ of participants reported missing at least one dose in the prior 4 days in the first week of therapy. This study's findings are consistent with a study of PEP following consensual sexual exposure in San Francisco, in which $16 \%$ of participants reported missing one or more doses in the 4 days prior to the week one visit and $78 \%$ completed the 28-day course [22]. There were no predictors of nonadherence in our study that would suggest targeting adherence intervention to specific PEP users. Our findings suggest that all users of PEP need adherence interventions that address the importance of taking each medication dose, not just completing 28 days of therapy.

Studies of PEP following consensual sex often focus on the potential for behavioral disinhibition, though reductions in risk behavior have been reported in the context of risk reduction counseling [31]. No studies address continuing HIV risk among sexual assault survivors or examine preexisting HIV-risk behavior patterns. In our study, baseline and ongoing HIV sexual risk behaviors were common and probably resulted in HIV acquisition in two participants. We found that the primary predictor of ongoing unprotected intercourse, which was very common, was prior unprotected intercourse. We believe that sexual assault survivors should have an assessment of their HIV risk history and should receive risk reduction counseling as appropriate during their post-rape care follow-up.

While reported symptoms are frequent in the PEP literature, there are no randomized studies examining this issue. Our study design, however, provided an opportunity to compare symptoms in participants who had been on PEP for 1-5 days with a group that had been on PEP for less than $24 \mathrm{~h}$ or not at all. We found that the baseline symptom rate was higher in the group with no or less PEP exposure at baseline, and then rates of reported symptoms during and after PEP completion equalized between both groups.
These intriguing findings suggest that many symptoms reported in PEP users may be related to the emotional impact of potential HIV exposure and trauma rather than the drugs themselves, at least with this specific two-drug regimen. Discussing this information with patients being offered PEP may help to normalize their experience. If providers understand this phenomenon, they may be better able to support their clients during their PEP course. This finding also highlights the importance of offering rape survivors appropriate psychosocial support, which may help them understand and cope with psychosomatic component of their symptoms that could otherwise impact their PEP adherence.

Substantial resources were required to achieve high follow-up and PEP completion rates. These included nurses who were comfortable with sexual assault and HIV issues, proactive follow-up, financial support for transportation, and flexible follow-up locations. The only literature reporting high follow-up rates are prospective studies and a study describing another proactive follow-up system in Amsterdam [32-34]. It is important to consider the resources required to provide comprehensive follow-up services when deciding to develop systems to initiate PEP.

The resource-intensive task of developing systems to provide access to expensive PEP medications, adherence and risk reduction counseling, and follow-up create a public health prioritization challenge, especially given that the efficacy of non-occupational PEP is unproven. However, these data and other studies do illustrate that, even in the context of PEP provision, risky sexual behaviors and seroconversions occur [29]. Therefore, PEP-related services should be provided in the context of comprehensive sexual assault, trauma and HIV prevention services to minimize HIV acquisition for sexual assault survivors. Specifically, early risk assessment and risk reduction counseling would provide an opportunity to address the larger context of HIV risk. Finally, sexual assault survivors who use PEP should be counseled that symptoms are common, usually subside over time, and may be related to stress. Normalizing this experience can reduce fear regarding potential PEP toxicity and may improve adherence.

Limitations of this study included a lack of randomization, limiting inferences about symptom association with PEP use. Additionally, while the regimen used in this study is likely to be the one available in resource-limited settings, it is being replaced by simpler regimens with less toxicity, limiting the ability to generalize these findings to more resource-rich contexts. We did not obtain consent to describe those who did not enroll in the study (i.e. how many patients were already HIV positive). The participants may have exhibited some degree of recall bias. Participants may also have exhibited a degree of response bias in that 
they might have offered responses that they felt pleased the interviewer.

Further research is needed to develop effective adherence counseling strategies for this population. This is particularly challenging since PEP may not always be initiated by providers with specialized training. Further research is also needed to develop effective risk assessment and risk reduction counseling strategies following sexual assault.

Acknowledgments Fazielah Bartlett, Nomthandazo Kate Makeleni, and Jostina Tandie Fipaza conducted the study and provided compassionate care for study participants. Ayesha Sasman coordinated the study. Stephen May prepared all study documents and helped with this manuscript. Felicity Mtshobile conducted data entry. Support for this study was provided by the National Institutes of Health (R01 MH61180, R01 MH61180-02-S2 and K23 MH071188), University of California, San Francisco-Gladstone Institute of Virology \& Immunology Center for AIDS Research (P30 AI027763), and the Fogarty International Center of the National Institutes of Health, University of California, Berkeley, School of Public Health, Division of Epidemiology (D43TW000003). Parts of the information contained in this manuscript were presented at: 12th Conference on Retroviruses and Opportunistic Infections, Boston, MA: February 2005 (abstract \#539), Third South African Gender Based Violence and Health Conference, Cape Town, South Africa: October 2005, and XVI International AIDS Conference, Toronto, Canada: August 2006 (abstract \#MOPDC03).

Open Access This article is distributed under the terms of the Creative Commons Attribution Noncommercial License which permits any noncommercial use, distribution, and reproduction in any medium, provided the original author(s) and source are credited.

\section{References}

1. Cardo DM, Culver DH, Ciesielski CA, et al. A case-control study of HIV seroconversion in health care workers after percutaneous exposure: Centers for Disease Control and Prevention Needlestick Surveillance Group. N Engl J Med. 1997;337:1485-90.

2. United Kingdom Health Department. HIV post-exposure prophylaxis: guidance from the UK Chief Medical Officers' Expert Advisory Group on AIDS. London, UK; 2000.

3. United States Centers for Disease Control. Antiretroviral Postexposure Prophylaxis After Sexual, Injection-Drug Use, or other Non-occupational Exposure to HIV in the United States: Recommendations from the U.S. Department of Health and Human Services. 2005; Atlanta, GA. http://www.cdc.gov/mmwr/pre view/mmwrhtml/rr5402a1.htm. Accessed 7 Jan 2010.

4. Myles J, Bamberger J. Offering HIV prophylaxis following sexual assault: recommendations for the State of California: The California HIV PEP after Sexual Assault Task Force in conjunction with the California State Office of AIDS. 2001; San Francisco, CA. http://www.cdph.ca.gov/programs/AIDS/Docu ments/RPT2004OfferingPEPFollowingNonOccupExp2004-06.pdf. Accessed 7 Jan 2010.

5. California Task Force on Non-Occupational PEP and the California Department of Health Services Office of AIDS. Offering HIV post-exposure prophylaxis (PEP) following non-occupational exposures: recommendations for health care providers in the state of California. Sacramento, CA; 2004.
6. New York State Department of Health. HIV prophylaxis following non-occupational exposure including sexual assault. 2005; New York, NY. http://www.hivguidelines.org/Content.aspx? pageID=78. Accessed 7 Jan 2010.

7. New York State Department of Health. HIV post-exposure prophylaxis for children beyond the perinatal period. 2004; New York, NY. http://www.hivguidelines.org/Content.aspx?pageID =78. Accessed 7 Jan 2010 .

8. Almeda J, Casabona J, Simon B, et al. Proposed recommendations for the management of HIV post-exposure prophylaxis after sexual, injecting drug or other exposures in Europe. Euro Surveill. 2004;9:35-40.

9. Ortega JA, Barbara JC, et al. Guidelines for non-occupational post-exposure HIV: prophylaxis Recommendations of GESIDA/ CEESCAT/National Plan on AIDS. Practice guidelines for the management of HIV infections (2000-2002). Spain: Ediciones Doyma-Madrid; 2002. p. 129-43.

10. The Western Cape Provincial Department of Health. Treatment guidelines for the use of post-exposure prophylaxis (PEP) for the prevention of the transmission of human immunodeficiency virus (HIV) in women and men who have been raped or sexually assaulted. Cape Town, South Africa; 2002.

11. Ministry of Health-Division of Reproductive Health, Republic of Kenya. National Guidelines: Medical Management of Rape/ Sexual Violence. 2004; Nairobi, Kenya. http://www.drh.go.ke/ documents/Guidelines_gender.pdf. Accessed 7 Jan 2010.

12. Brown University AIDS Program and the Rhode Island Department of Health Non-occupational HIV PEP Task Force. Nonoccupational human immunodeficiency virus post-exposure prophylaxis guidelines for Rhode Island healthcare practitioners. 2002; Providence, RI. http://www.health.ri.gov/disease/NPEP 072202.pdf. Accessed 7 Jan 2010.

13. Puro V. Post-exposure prophylaxis for HIV infection: Italian registry of post-exposure prophylaxis. Lancet. 2000;355:155-67.

14. Department of Health, Republic of South Africa. Policy guideline for the management of transmission of human immunodeficiency virus (HIV) and sexually transmitted infections in sexual assault. 2003; Pretoria, South Africa. http://www.doh.gov.za/aids/docs/ rape-protocol.html. Accessed 7 Jan 2010.

15. Myles JE, Hirozawa A, Katz MH, Kimmerling R, Bamberger JD. Postexposure prophylaxis for HIV after sexual assault. JAMA. 2000;284:1516-8.

16. Wiebe ER, Comay SE, McGregor M, Ducceschi S. Offering HIV prophylaxis to people who have been sexually assaulted: 16 months' experience in a sexual assault service. CMAJ. 2000; $162: 641-5$

17. Linden JA, Oldeg P, Mehta SD, McCabe KK, LaBelle C. HIV postexposure prophylaxis in sexual assault: current practice and patient adherence to treatment recommendations in a large urban teaching hospital. Acad Emerg Med. 2005;12:640-6.

18. Olshen E, Hsu K, Woods ER, Harper M, Harnisch B, Samples CL. The use of HIV postexposure prophylaxis in adolescent sexual assault victims. Arch Pediat Adol Med. 2006;160:674-80.

19. Kerr E, Cottee C, Chowdhury R, Jawad R, Welch J. The Haven: a pilot referral centre in London for cases of serious sexual assault. BJOG. 2003;110:267-71.

20. Limb S, Kawsar M, Forster GE. HIV post-exposure prophylaxis after sexual assault: the experience of a sexual assault service in London. Int J STD AIDS. 2002;13:602-5.

21. Templeton DJ, Davies SC, Garvin AL, Garsia RJ. The uptake of HIV post-exposure prophylaxis within a sexual assault setting in Sydney, Australia. Int J STD AIDS. 2005;16:108-11.

22. Kahn JO, Martin JN, Roland ME, et al. Feasibility of postexposure prophylaxis (PEP) against human immunodeficiency virus infection after sexual or injection drug use exposure: the San Francisco PEP Study. J Infect Dis. 2001;183:707-14. 
23. Schechter M, do Lago RF, Mendelsohn AB, Moreira RL, Moulton LH, Harrison LH. Behavioral impact, acceptability, and HIV incidence among homosexual men with access to postexposure chemoprophylaxis for HIV. J Acquire Immune Defic Syndr. 2004;35:519-25.

24. Sikka AM, Nyandiko WM, Mwangi A, et al. The structure and outcomes of a HIV post-exposure prophylaxis program in a high HIV prevalence setup in Western Kenya. J Acquir Immune Defic Syndr. 2009;51:47-53.

25. Carries S, Muller F, Muller FJ, Morroni C, Wilson D. Characteristics, treatment and antiretroviral prophylaxis adherence of South African rape survivors. J Acquir Immune Defic Syndr. 2007;46:68-71.

26. Kilonzo N, Taegtmeyer M, Molyneux C, Kibaru J, Kimonji V, Theobald S. Engendering health sector responses to sexual violence and HIV in Kenya: results of a qualitative study. AIDS Care. 2008;20:188-90.

27. Vetten L, Haffejee S. Supporting rape survivors in adhering to post-exposure prophylaxis (PEP) to prevent HIV infection: the importance of psychosocial counseling and support. South Afr J HIV Med. 2008;9:21-4.

28. Kim JC, Askew I, Muvhango L, et al. Comprehensive care and HIV prophylaxis after sexual assault in rural South Africa: the Refentse intervention study. BMJ. 2009;13:1559-62.
29. Christofedes N, Muirhead D, Jewkes RK, Penn-Kekana L, Conco DN. Other patients are really in need of medical attention-the quality of health services for rape survivors in South Africa. Bull World Health Organ. 2005;83:495-502.

30. Garcia MT, Figueiredo RM, Moretti ML, Resende MR, Bedoni AJ, Papaiordanou PM. Postexposure prophylaxis after sexual assaults: a prospective cohort study. Sex Transm Dis. 2005;32: 214-9.

31. Martin JN, Roland ME, Neilands TB, et al. Use of postexposure prophylaxis against HIV infection following sexual exposure does not lead to increases in high-risk behavior. AIDS. 2004; 18:787-92.

32. Sonder GJ, Van Den Hoek A, Regez RM, et al. Trends in HIV postexposure prophlaxis prescription and compliance after sexual exposure in Amsterdam, 2000-2004. Sex Transm Dis. 2006;33: 288-93.

33. Roland ME. A model for community-wide delivery of postexposure prophylaxis after potential sexual exposure to HIV. Sex Transm Dis. 2007;34(5):288-93.

34. Roland ME, Neilands TN, Krone MR, et al. Seroconversion following non-occupational post-exposure prophylaxis against human immunodeficiency virus. Clin Infect Dis. 2005;41: 1507-13. 